\title{
A METHOD OF ASSESSING MATERNAL EFFICIENCY FOR SOCIO-MEDICAL SURVEYS
}

\author{
BY \\ E. JEAN THWAITES and IAN SUTHERLAND \\ From the Institute of Social Medicine, Oxford
}

(RECEIVED FOR PUBLICATION JUNE 13. 1951)

In discussing the importance of the home and social environment to the health of the child, Burn (1947) said:

- If I were to ask what each one of us meant by " environment" in respect of child life, I think I know the mental picture which would be conjured up-that of house and district in which the child lived, the state of the backyard and lavatory, the degree of atmospheric pollution of the air he breathed, the purity of the water and the milk he drank, the sanitation of the school premises, etc., etc. This is the truth, but not the whole truth. Environment, defined by the dictionary as "that which surrounds" includes social and psychological influences, which though as intangible and imponderable as air, are nevertheless of decisive importance. It is almost true to say that the infant's environment is his mother.'

The suggestion that the standard of maternal care might be of greater importance to the health and welfare of the young child than any other single influence was strongly advanced by Paton and Findlay (1926). Much valuable data on infant mortality, which support the same suggestion, were put forward by Elderton $(1925,1928)$. Paton and Findlay were the first to attempt an explicit assessment of this standard.

\footnotetext{
- The factor of maternal character or efficiency is extraordinarily difficult to define and difficult to assess, but a worker of experience is able to classify mothers in this respect into good, bad and indifferent. When the children are repeatedly found to be dirty or verminous, badly clothed and left in bed until all hours of the day, when the house is constantly dirty and uncared for, the mother, without doubt, is inefficient.'
}

It is the purpose of the present paper to indicate how a reliable assessment of maternal efficiency may be made, to put forward methods whereby a mother may be assigned a numerical score to represent the 'intangible and imponderable', and to give three examples showing how maternal efficiency is associated with the health and environment of the infant.

\section{Qualitative Assessments}

It is evident that the definition and assessment of maternal efficiency must rest ultimately upon a subjective basis, and it may be suggested that such an assessment has limited scientific value. Yates (1949) makes the following comments.

\section{- Physical measurements are more objective, but qualitative observations are often more capable of summing up the salient features of a complex situation. Thus a qualitative grading by the investigator of the degree of dampness of a house is likely to be more effective than any physical measurements designed to determine the degree of dampness. Moreover by proper standardization and calibration among investigators qualitative observations can themselves be made objective.'}

The last sentence represents the crux of the problem. The fundamental uncertainty in any subjective assessment is that another person. or the same person on a different occasion, may make a different evaluation. The more this uncertainty can be reduced, the greater will be the scientific value of the assessment. In this connexion it is worth noting that the particular relevance of such an assessment is in relation to the survey of which it forms a part, and so it is necessary primarily to achieve consistent standards within that survey. If the method derived can also ensure consistent results from one survey to another, so much the better, but this is a secondary consideration.

Although it is difficult to maintain a consistent standard in assessing qualitative factors, the following recommendations may be made. (1) The quality which is to be assessed should be clearly defined. (2) Where possible, several tangible manifestations 
of the quality should be appraised, in preference to the quality itself. (3) The various categories should be clearly defined, so as to differentiate between borderline cases, which always present special difficulties. (4) The number of people compiling the records should be kept to an absolute minimum. If more than one person is needed there must be frequent consultation between them, and crosschecking, particularly for borderline cases. (5) For preference the assessments should be based upon several independent observations during the survey period. It is upon these lines that we have attempted to grade the mother's efficiency.

\section{A Method of Assessing Maternal Efficiency}

We have continued to use the term 'maternal efficiency', which was introduced by Paton and Findlay, defining this quality as the ability of a mother to cope with and care for her child, and interpreting ' ability' in terms of achievement, not in terms of potentiality. We were concerned to discover the factors which influence the health and development of the child, and so it was the care which the child actually received which was studied rather than the imprecise concept of the mother's basic capacity to manage.

The purposes and methods of the Child Health Survey, which was begun by the Institute of Social Medicine, Oxford, in 1944, have already been outlined (Ryle, 1948; Thwaites, 1950). From the outset it was agreed that an assessment of maternal efficiency was fundamental, and much discussion was devoted to the best method of making it. A survey of the literature and consultations with interested persons in this country suggested that any assessment should be based at least upon the following five factors, which are either indicative of, or (in the case of health) contribute towards, the mother's achievement for her child: state of child, diet of child, attitude of mother to child, state of home and health of mother.

It was therefore decided to class each mother as ' good ', 'fair' or 'poor' on each of these counts from observations made during three visits to the home (not more than one of these being by appointment) during the first year of the child's life. Similar assessments have been made each year until the child attained the age of 5 or resigned from the survey. This paper is based upon assessments covering the first year of life of 580 Oxford babies.

After a certain time, it was possible for the one observer* to know from experience what each

\footnotetext{
* For the period October, 1944, to June, 1946, the social reporting was in the hands of Miss Elisabeth J. Williams. After a month of joint work. the reporting has been the sole responsibility of one of the u riters (F.J.T.).
}

category meant. Though it is by no means easy to frame working definitions, the following attempt has been made.

\section{Working Definitions for the Assessments}

State of Child. This was classified as good, fair or poor.

GooD. If the child itself was clean and had clean and adequate clothing. It was still considered to be good if a child at the crawling stage had top dirt ' only, provided that the child had been clean on previous visits; due allowance was also made for 'play dirt' in the older age groups.

FAIR. If the child was dirty or else had dirty clothing, the latter being more usual. This assessment was made if a child of 6 weeks had dirty nails, but not if a child, who had previously been clean, was found to have dirty nails during the crawling period.

Poor. If ingrained dirt and dirty clothing were found on each occasion.

When in doubt, the lower assessment has been recorded. No child was marked down for pediculosis capitis per se. However, with one exception, the children who were independently noted at the clinical examinations as having pediculi, had come from dirty homes.

Diet of Child. This was classified as good, fair. or poor.

GooD. If the diet was adequate in amount and kind, and given at reasonably regular intervals. If an infant was not receiving regular vitamin supplements, it was verified that he was getting these in natural foods.

FAIR. If there was evidence of any one of the following: gross overfeeding or underfeeding; complete disregard of any timing; diet inadequate in vitamins or any other essential constituent.

POOR. If marked down on two or more of the above points; and if no care was taken at all, e.g. perpetual bread and margarine.

Again the principle of marking down the borderline assessments has been observed. This was expedient since the general level of nutrition was high, but it is realized that it may not be generally applicable. Some salutary observations are made in the report of the United Nations Food and Agricultural Organization on Dietary Surveys: Their Technique and Interpretation (Norris, 1949).

Attitude of Mother to Child. This assessment was considered essential in order to differentiate the efficient mother from the efficient housewife. The needs for the mental welfare of the child, as set forth by Anderson (1948) may be grouped as follows: (1) security; (2) discipline and habit training; 
(3) love and affection (' wantedness '); (4) equality with and 'sameness" to others; (5) opportunity and space to indulge in noisy, active play, possessions.

The attitude of the mother was classified as good, fair or poor.

GooD. If all these five needs were apparently being met.

FAIR. If one or two appeared to be lacking.

PoOR. If three or more of the above were lacking.

Whereas the other assessments have been downgraded in borderline cases, the mother was always given the benefit of any doubt in this instance. In order to guard against possible errors of judgment due to personal bias, the opinions of other workers, such as health visitors, almoners and the superintendents of the day nurseries, were sought as a reinforcement where this was felt to be necessary.

State of Home. This was classified as good, fair or poor.

Good. When the home was clean and reasonably tidy. If the mother was house-proud to the extent of unduly limiting active play she was marked down on the assessment of 'attitude', though not, of course, on the assessment of 'state of home'.

FAIR. When the home was fairly clean: the intermediate grade.

PoOR. When the house was dirty and smelly, and no attempt was made at housework; for instance if food was permanently on the table and beds never made.

Though the first visit might be by appointment, the majority of visits were unexpected. The kitchen and bedrooms were usually seen at least once, and the other rooms on several occasions and at different times of the day. Every attempt was made to prevent first impressions colouring the picture; for instance a new ' prefab.' looked so much cleaner than one of the older houses with shabby Victorian furniture, but might well not be so. The lower assessment has been recorded where there was uncertainty.

Health of Mother. This was classified as good, fair or poor.

GooD. If the mother was in good health and able to continue normal household duties. If a mother became pregnant again, and said she felt well, or if she had not more than two weeks" illness (for instance one or two colds) she was still placed in this category.

FAIR. This assessment included the mother who had (1) from two to four weeks' illness, but who was otherwise able to continue normal duties;
(2) chronic complaints, e.g. controlled diabetes, ' nerves ', deafness; (3) minor gynaecological complaints, anaemia; (4) residual paralysis, necessitating the use of a caliper, or orthopaedic complaints.

Poor. If the mother's function as a housewife was interfered with by serious complaints, such as (1) rheumatism with heart involvement; (2) thyrotoxicosis involving hospital treatment or operation; (3) tuberculosis, under treatment; (4) blindness within the meaning of the Blind Persons Act (1920).

Though the clinician who saw the children was available for consultation, the recorded assessment was based on the mother's description. Known borderline cases have been down-graded but it is possible that health has not been scaled down often enough. For instance, after frequent pregnancies, some mothers had probably not been fighting fit for years, and so had no criterion of health, although they said they had 'no complaints'. A standard comment of the mothers was 'I have to keep well'.

\section{A Method of Deriving a Score for Maternal Efficiency}

When the five assessments had been made, there arose the problem of combining them into a single measure. Unless each was taken to be of equal value as an indicator of maternal efficiency some decision was necessary as to their relative importance. There was little unanimity in the views of those whom the Institute consulted on this topic, and so it was resolved to use a statistical approach known as factor analysis (Holzinger and Harman, 1941). In this approach the data themselves determine what score should be given to each of the five factors. Each of the assessments was regarded as a more or less close measure of the underlying concept of maternal efficiency. The fundamental assumption was then made that the assessments which were most closely related to each other were also most closely related to the underlying concept. From calculations based on the interrelations of the five assessments, each was assigned a score, which was indicative of the closeness of the association between it and the underlying concept.

Details of Computation. The particular technique used was the method of principal factors. The first principal factor only was calculated, and taken to be that of 'maternal efficiency'. One of us (E. J. T.) felt that there was a greater gulf between the 'poor' and ' fair ' grades than between 'fair' and 'good'. Hence the correlation between each pair of assessments was estimated from a formal calculation with working units of 1,0 and -2 assigned arbitrarily to the good, fair and poor grades respectively. The calculations were 
made on the 580 sets of five assessments, and the correlation coefficients found were as follows:

\begin{tabular}{|c|c|c|c|c|}
\hline & $\begin{array}{l}\text { Diet } \\
\text { of } \\
\text { Child }\end{array}$ & $\begin{array}{l}\text { Attitude } \\
\text { of } \\
\text { Mother }\end{array}$ & $\begin{array}{l}\text { State } \\
\text { of } \\
\text { Home }\end{array}$ & $\begin{array}{l}\text { Health } \\
\text { of } \\
\text { Mother }\end{array}$ \\
\hline $\begin{array}{l}\text { State of child } \\
\text { Diet of child } \\
\text { Attitude of mother } \\
\text { State of home }\end{array}$ & 0.565 & $\begin{array}{l}0 \cdot 606 \\
0 \cdot 555\end{array}$ & $\begin{array}{l}0 \cdot 706 \\
0 \cdot 560 \\
0 \cdot 497\end{array}$ & $\begin{array}{l}0 \cdot 243 \\
0 \cdot 285 \\
0 \cdot 256 \\
0 \cdot 223\end{array}$ \\
\hline
\end{tabular}

The communalities needed for the analysis were estimated from the averages of all triads.

Scores. The following system of scores resulted from the analysis, giving a possible maximum of 100 . Since it was felt that there was a greater gulf between the 'poor' and 'fair' grades than between 'fair' and ' good', this was made a feature of the system of scores, by giving the 'fair' grade two-thirds of the scores for the ' good' grade.

\begin{tabular}{|c|c|c|c|c|}
\hline & & Good & Fair & Poor \\
\hline $\begin{array}{l}\text { State of child } \\
\text { Diet of child } \\
\text { Attitude of mother } \\
\text { State of home } \\
\text { Health of mother }\end{array}$ & $\begin{array}{l}\cdots \\
\cdots \\
\cdots \\
\cdots\end{array}$ & $\begin{array}{r}32 \\
25 \\
19 \\
19 \\
5\end{array}$ & $\begin{array}{r}22 \\
16 \\
13 \\
13 \\
3\end{array}$ & $\begin{array}{l}\mathbf{0} \\
\mathbf{0} \\
\mathbf{0} \\
\mathbf{0} \\
\mathbf{0}\end{array}$ \\
\hline
\end{tabular}

The order of importance assigned to the five factors by the analysis is the order in which for convenience they have already been considered in this study.

As a matter of interest, E.J.T., having no knowledge of the results of this analysis by I.S., was invited to assign scores, totalling to 20 , to the five factors to represent what she considered to be their relative importance as measures of maternal efficiency. Her scores were as follows:

\begin{tabular}{|c|c|c|c|}
\hline & & E.J.T. & Factor Analysis \\
\hline $\begin{array}{l}\text { State of child } \\
\text { Diet of child } \\
\text { Attitude of mother } \\
\text { State of home } \\
\text { Health of mother }\end{array}$ & $\begin{array}{l}\cdots \\
\cdots \\
\cdots \\
\cdots\end{array}$ & $\begin{array}{l}6 \\
5 \\
3 \\
4 \\
2\end{array}$ & $\begin{array}{l}6 \\
5 \\
4 \\
4 \\
1\end{array}$ \\
\hline
\end{tabular}

The correspondence is very close. Although it would be unwise to make too much of it, the result certainly suggests that factor analysis is a realistic technique to apply to this problem.

\section{Scores for Maternal Efficiency}

Table 1 shows how many of the 580 mothers were classified as good, fair or poor on each of the five counts. It is clear that the general level of mothercraft was high, since the majority of the mothers
TABLE 1

Classification of 580 Mothers according to Five INDICES OF MATERNAL EFFICIENCY

\begin{tabular}{|c|c|c|c|c|}
\hline & Good & Fair & Poor & Total \\
\hline $\begin{array}{l}\text { State of child . } \\
\text { Diet of child . } \\
\text { Attitude of mother }\end{array}$ & $\begin{array}{l}476 \\
503\end{array}$ & $\begin{array}{l}97 \\
75\end{array}$ & $\begin{array}{l}7 \\
2\end{array}$ & $\begin{array}{l}580 \\
580\end{array}$ \\
\hline $\begin{array}{l}\text { to child } \\
\text { State of home } \\
\text { Health of mother }\end{array}$ & $\begin{array}{l}466 \\
418 \\
457\end{array}$ & $\begin{array}{l}109 \\
137 \\
120\end{array}$ & $\begin{array}{r}5 \\
25 \\
3\end{array}$ & $\begin{array}{l}580 \\
580 \\
580\end{array}$ \\
\hline
\end{tabular}

were graded 'good' and very few were classed as 'poor'. It was expected when the Child Health Survey started that this would be so for a group of volunteers living in Oxford. This raises the question whether more stringent criteria should have bsen used in order to yield a more balanced classification. This was deliberately not done because it would have given undue prominence to the social worker's personal opinions of what was desirable and what was undesirable in the child's environment.

Table 2 shows the maternal efficiency scores derived from the five indices. No fewer than 320

TABle 2

Classification of 580 Mothers According to Scores for Maternal Efficiency Based Upon

FIVE ASSESSMENTS

\begin{tabular}{|c|c|c|}
\hline Score* & Number of Mothers & Percentage \\
\hline $\begin{array}{cc}100 & \ldots \\
98 & \ldots \\
90-95 & \ldots \\
80-89 & \ldots \\
70-79 & \ldots \\
\text { Under } & 70\end{array}$ & $\begin{array}{l}320 ! 370 \\
50 ; \\
78 \\
51 \\
32 \\
49\end{array}$ & $\begin{array}{r}55 \cdot 2 \\
8 \cdot 6 \\
13 \cdot 63 \cdot 8 \\
8 \cdot 8 \\
5 \cdot 5 \\
8 \cdot 4\end{array}$ \\
\hline & 580 & $99 \cdot 9$ \\
\hline
\end{tabular}

- By factor analysis.

mothers $(55 \cdot 2 \%)$ were classed as ' good' on all five and so score 100 . A further $50(8.6 \%)$ were only marked down by two points on account of fair health. At the other end of the scale were 49 mothers who scored less than 70 . The lowest score recorded was 3 for a mother who had fair health, but was otherwise graded poor. These figures again bring out the high standards in the group under survey.

\section{Choice of Methods for Assessing and Scoring Maternal Efficiency}

At this point it was necessary to consider whether the procedures originally decided upon, and outlined above, for grading maternal efficiency should 
be modified in the light of experience. The principal modification concerns maternal health. During the course of the survey, one of us (E.J.T.) became increasingly convinced that ill-health in the mother was frequently overcome and so made little difference to her efficiency; for this reason health should not be used as an indicator of a mother's efficiency. Moreover, health is not, like the other four, a direct measure of the mother's achievement but a measure of her potentiality in relation to the child. The assessment is thus of a different character from the others, and this is one of the reasons why such low scores are allotted to maternal health by the factor analysis. It was therefore decided to omit maternal health from the five assessments and to base the score for maternal efficiency upon the remaining four. This has an added advantage. By using a measure of efficiency which does not incorporate maternal health explicitly it is possible to regard the mother's health and her efficiency as two separate influences upon the health and development of her child, and to decide upon their relative importance.

It was next necessary to consider whether a simpler method of scoring would not be as satisfactory as the complex one already outlined. Whatever method was adopted, all those mothers who were classed as 'good' on the four assessments of achievement had to score full marks. - These numbered $371(64 \%$ of the total). Thus the only difference between alternative methods was the way in which they grouped the remaining $36 \%$; this fact considerably lessened the scope for any variant of method.

The simplest alternative was to give an equal weight to each assessment, say scoring 3 for ' good ', was tried out and was found to have a negligible effect on the original grouping. This shows that for the study of mothers whose standards are as high as those of the present series a scoring system based upon factor analysis is unnecessarily elaborate, and gives little extra discrimination between mothers compared with a simple scheme. The approach by factor analysis has been outlined here for two 2 for ' fair' and 1 for 'poor' on each. This system

reasons. First, it justifies in this particular instance the use of a simpler scoring system with equal weights for each assessment, a step which would otherwise have appeared arbitrary. Secondly, it illustrates a technique for combining a number of assessments which should be useful in other sociomedical surveys. It has already been used in studies of physical constitution (Burt and Banks, 1947), and the assessment of physical fitness (Cureton, 1947) as well as in its original field of application to psychology.

A number of other methods of scoring were investigated. They all gave similar results, and there was no reason to prefer any of them to the very simple pattern just suggested. Consequently this was adopted for scoring maternal efficiency. Table 3 shows the distribution of the mothers according to this revised score for efficiency.

TABLE 3

Classification of 580 Mothers According to Scores for Maternal Efficiency Based Upon FOUR ASSESSMENTS

\begin{tabular}{|c|c|c|}
\hline Score* & Number of Mothers & Percentage \\
\hline $\begin{array}{r}12 \\
11 \\
10 \\
9 \\
8 \\
7 \\
6 \\
5 \\
4\end{array}$ & $\begin{array}{r}371 \\
81 \\
48 \\
31 \\
31 \\
11 \\
3 \\
3 \\
1\end{array}$ & $\begin{array}{l}64 \cdot 0 \\
14 \cdot 0 \\
8 \cdot 3 \\
5 \cdot 3 \\
5 \cdot 3 \\
1 \cdot 9 \mid \\
0 \cdot 5 \cdot 8 \cdot 4 \\
0 \cdot 5 \\
0 \cdot 2\end{array}$ \\
\hline & 580 & $100 \cdot 0$ \\
\hline
\end{tabular}

*Score: 3 = good, 2 = fair, 1 = poor.

Maternal Efficiency According to Sharing the Home. As a first example of the use of the maternal efficiency score we decided to see whether it varied if the family unit shared its accommodation with others. The family unit was defined as the survey child, together with any brothers or sisters, and the parents. The figures in Table 4 show that family units living on their own achieved the highest

TABLE 4

Maternal Efficiency Related to Shared Accommodation

\begin{tabular}{|c|c|c|c|c|c|c|c|}
\hline \multicolumn{2}{|l|}{ Family Unit } & \multicolumn{4}{|c|}{ Percentages of Mothers Scoring } & Total & No. of Mothers \\
\hline $\begin{array}{l}\text { Living alone .. } \\
\text { Sharing with lodgers .. } \\
\text { Sharing with relatives } \\
\text { Living in rooms }\end{array}$ & $\begin{array}{c}12 \\
68 \cdot 3 \\
63 \cdot 6 \\
60 \cdot 8 \\
46 \cdot 5\end{array}$ & $\begin{array}{c}11 \\
12 \cdot 7 \\
15 \cdot 5 \\
12 \cdot 7 \\
16 \cdot 3\end{array}$ & $\begin{array}{r}10 \\
7 \cdot 9 \\
7 \cdot 8 \\
8 \cdot 9 \\
11 \cdot 6\end{array}$ & $\begin{array}{l}9 \\
4 \cdot 0 \\
7 \cdot 3 \\
5 \cdot 1 \\
4 \cdot 7\end{array}$ & $\begin{array}{c}8 \text { or less } \\
7 \cdot 1 \\
5 \cdot 8 \\
12 \cdot 7 \\
20 \cdot 9\end{array}$ & $\begin{array}{l}100 \cdot 0 \\
100 \cdot 0 \\
100 \cdot 2 \\
100 \cdot 0\end{array}$ & $\begin{array}{r}252 \\
79 \\
206 \\
43\end{array}$ \\
\hline All family units & $64 \cdot 0$ & $14 \cdot 0$ & $8 \cdot 3$ & $5 \cdot 3$ & $8 \cdot 4$ & $100 \cdot 0$ & 580 \\
\hline
\end{tabular}


TABLE 5 .

Maternal Efficiency Related to Non-specific Infections in the Child in the First Year

\begin{tabular}{|c|c|c|c|c|c|c|c|c|}
\hline \multirow{2}{*}{\multicolumn{2}{|c|}{$\begin{array}{l}\text { Number of Non-specific } \\
\text { Infections in Child }\end{array}$}} & \multicolumn{5}{|c|}{ Percentages of Mothers Scoring } & \multirow[b]{2}{*}{ Total } & \multirow[b]{2}{*}{ No. of Mother } \\
\hline & & 12 & 11 & 10 & 9 & 8 or less & & \\
\hline $\begin{array}{ll}0-1 & . \\
2-3 & \therefore \\
4 & \text { or more }\end{array}$ & $\begin{array}{l}. \\
\cdots \\
.\end{array}$ & $\begin{array}{l}68 \cdot 8 \\
63 \cdot 5 \\
39 \cdot 0\end{array}$ & $\begin{array}{l}11 \cdot 7 \\
15 \cdot 7 \\
20 \cdot 3\end{array}$ & $\begin{array}{r}9 \cdot 3 \\
4 \cdot 1 \\
16 \cdot 9\end{array}$ & $\begin{array}{l}4.9 \\
5.6 \\
6.8\end{array}$ & $\begin{array}{r}5 \cdot 2 \\
11 \cdot 2 \\
16 \cdot 9\end{array}$ & $\begin{array}{r}99.9 \\
100 \cdot 1 \\
99.9\end{array}$ & $\begin{array}{r}324 \\
197 \\
59\end{array}$ \\
\hline All children & . & $64 \cdot 0$ & $14 \cdot 0$ & $8 \cdot 3$ & $5 \cdot 3$ & $8 \cdot 4$ & $100 \cdot 0$ & 580 \\
\hline
\end{tabular}

standards of efficiency; $68 \%$ of the mothers scored full marks of 12. The lowest levels of score were among those living in 'rooms', the corresponding percentage being only $46 \%$.

Maternal Efficiency and Non-specific Infections in the Infant. Table 5 shows that there is a definite relation between maternal efficiency and the number of non-specific infections (colds, etc.) in the first year of life. Where the child had no infections, or only one, nearly seven out of 10 of the mothers scored full marks. Where the child had four or more infections, only four out of $\mathbf{1 0}$ mothers scored full marks. Further investigation is of course necessary to decide whether there is any causative connexion between these two factors, or if some other influence, such as crowding, is responsible for the association.

Maternal Efficiency and Gastro-enteritis in the Infant. The third example (Table 6) shows that there was no relationship between maternal efficiency and the liability of the child to contract gastroenteritis in the first year. The variations between the two lines of percentages could well have arisen by chance. It will, however, be shown in a later report that children are less liable to contract gastro-enteritis while still entirely breast-fed. Since the type of feeding was not included as such in our assessment of maternal efficiency, its influence is not revealed by this index, and will be studied separately.

\section{Summary and Conclusions}

Several previous investigators into the problem of child health have stressed the importance of the 'efficiency' of the mother as an influence upon the health and development of the child. In connexion with its Child Health Survey, the Institute of Social Medicine in Oxford has devised a method of assessing this quality, which is presented in this paper, with examples of its use.

'Maternal efficiency' is defined as 'the ability of a mother to cope with and care for her child'. Emphasis is laid throughout on assessing the mother's actual achievement in relation to her child, rather than her basic capacity or her intentions.

An index of maternal efficiency was first derived from five separate assessments of the mother and of the environment which she created for the child, these assessments being combined by the statistical technique of factor analysis.

After due consideration of this index it was decided to omit the assessment of maternal health and base a revised index upon four assessments only, namely, the state of the child, the diet of the child, the mother's attitude to the child and the state of the home. The standards of assessment are set out. At the same time it was decided that the technique for combining the assessments was unnecessarily complicated in the present instance, and that it would be a practical advantage to replace it by a much simpler system.

TABLE 6

Maternal Efficiency Related to Gastro-Entermis in the Chimd in the First Year

\begin{tabular}{|c|c|c|c|c|c|c|c|}
\hline \multirow{2}{*}{$\begin{array}{l}\text { Gastro-enteritis in } \\
\text { Child }\end{array}$} & \multicolumn{5}{|c|}{ Percentages of Mothers Scoring } & \multirow[b]{2}{*}{ Total } & \multirow[b]{2}{*}{ No. of Mothers } \\
\hline & 12 & 11 & 10 & 9 & 8 or less & & \\
\hline $\begin{array}{l}\text { No attack } \\
\text { One or more attacks }\end{array}$ & $\begin{array}{l}63 \cdot 3 \\
66 \cdot 2\end{array}$ & $\begin{array}{l}14 \cdot 1 \\
13 \cdot 5\end{array}$ & $\begin{array}{r}7 \cdot 6 \\
10 \cdot 5\end{array}$ & $\begin{array}{l}6 \cdot 3 \\
2 \cdot 3\end{array}$ & $\begin{array}{l}8 \cdot 7 \\
7 \cdot 5\end{array}$ & $\begin{array}{l}100 \cdot 0 \\
100 \cdot 0\end{array}$ & $\begin{array}{l}447 \\
133\end{array}$ \\
\hline 11 children & $64 \cdot 0$ & $14 \cdot 0$ & $8 \cdot 3$ & $5 \cdot 3$ & $8 \cdot 4$ & $100 \cdot 0$ & 580 \\
\hline
\end{tabular}


Examples are given of the relation between the revised index of maternal efficiency and three aspects of the child's environment and health.

We are much indebted to the late Professor J. A. Ryle and Dr. W. T. Russell, who were responsible for instituting the Child Health Survey and for the basis of this method of assessing maternal efficiency. We should also like to thank Dr. Alice Stewart and Dr. R. W. Parnell for their comments on the draft of this paper.

\section{REFERENCES}

Anderson, C. W. (1948). Publ. Hlth., Lond., $62,47$. Burn, J. L. (1947). J. R. Inst. publ. Hlth., 10, 325.

Burt, C. and Banks, C. (1947). Ann. Eugen., Camb., 13, 238.
Cureton, T. K. (1947). ' Physical Fitness Appraisal and Guidance.' London.

Elderton, E. M. (1925). Ann. Eugen., Camb.. 1, 139; 277.

(1928). Ibid., 3, 96.

F.A.O. Nutritional Studies No. 4 (1949). A report prepared by Thelma Norris, Nutrition Division, F.A.O., U.N. Geneva.

Holzinger, K. J. and Harman, H. H. (1941). ' Factor Analysis.' Chicago.

Paton, D. N. and Findlay, L. (1926). Spec. Rep. Ser. med. Res. Coun., Lond., No. 101.

Ryle, J. A. (1948). ' 'Changing Disciplines.' London. Thwaites, E. J. (1950). Archives of Disease in Childhood, $25,193$.

Yates, F. (1949). ' 'Sampling Methods for Censuses and Surveys.' London. 